\title{
Potencialidades do Geoturismo para a Criação de uma Nova Segmentação Turística no Brasil
}

\author{
Gilmara Barros da Silva \\ Rafaely Moreira Sabbá Neivab \\ Ricardo Eustáquio Fonseca Filhoc \\ Marcos Antonio Leite do Nascimento ${ }^{d}$
}

\section{Resumo}

O turismo como atividade econômica se apresenta através de segmentos que agregam quem produz, quem distribui e quem consome os serviços em um dado espaço. O Geoturismo surge como uma proposta de um novo segmento, que valoriza os patrimônios natural e cultural por meio de visita e interpretação de atrativos abióticos. Neste sentido, propõe-se a discussão do Geoturismo enquanto segmento turístico sob os auspícios do marco teórico do Ministério do Turismo. Para tanto, foi realizada pesquisa bibliográfica e documental das expressões "geoturismo" e "segmento turístico" em produções científicas e técnicas nas plataformas Google Scholar, Scopus e Biblioteca Digital Brasileira de Teses e Dissertações. Os resultados demonstram que não há um consenso entre estudiosos sobre a classificação do Geoturismo como segmento turístico, mas os pressupostos do MTUR dão subsídios para que seja reconhecido e priorizado nas políticas públicas de regionalização e sustentabilidade no futuro. Recomenda-se a construção de uma rede integrada de oferta e demanda geoturística, em níveis local, regional e nacional, para que a modalidade seja elencada e validada como segmento turístico.

Palavras-chave: Segmentação turística; Segmentação da oferta turística; Geoturismo.

\section{Abstract \\ Potentialities of Geotourism for the creation of a new tourist segmentation in Brazil}

The tourism as an economic activity presents itself in segments that assemble those who produce, distribute, and consume the services in a space. Geotourism appears as a proposal for a new segment, which valorizes natural and cultural heritage by visiting and interpretating abiotic attractions. This paper proposes the discussion of Geotourism as a tourist segment under the auspices of the theoretical framework of the Ministério do

a. Doutoranda em Turismo pela Universidade Federal do Rio Grande do Norte (UFRN), Natal, Rio Grande do Norte, Brasil. Docente do curso de Técnico em Guia de Turismo na Escola Estadual José Bezerra Cavalcanti, Santa Cruz, Rio Grande do Norte, Brasil. E-mail: gilmarabarross@gmail.com

b. Mestranda em Turismo pela Universidade Federal do Rio Grande do Norte (UFRN), Natal, Rio Grande do Norte, Brasil. Docente do eixo de Turismo, Hospitalidade e Lazer do Instituto Federal do Pará, Altamira, Pará, Brasil. E-mail: rafaely.neiva@ifpa.edu.br

c. Doutor em Ciências Naturais pela Universidade Federal de Ouro Preto (UFOP), Ouro Preto, Minas Gerais, Brasil. Docente do Bacharelado em Turismo e do Mestrado em Turismo e Patrimônio da UFOP, Ouro Preto, Minas Gerais, Brasil.

d. Doutor em Geodinâmica pela Universidade Federal do Rio Grande do Norte (UFRN), Natal, Rio Grande do Norte, Brasil. Docente do curso de Geologia da Universidade Federal do Rio Grande do Norte, Natal, Rio Grande do Norte, Brasil. E-mail: marcos.leite@ufrn.br 
Turismo (MTUR). For this purpose, a bibliographical and documentary research of the expressions "geotourism" and "tourist segment" was carried out in scientific and technical productions on the Google Scholar, Scopus, and Biblioteca Digital Brasileira de Teses e Dissertações platforms. The results suggest the lack of consensus among Geotourism researchers over its classification as a tourist segment, but MTUR assumptions provide subsidies for it to be recognized and prioritized in public policies of regionalization and sustainability in the future. We recommend the construction of an integrated network of geotourist supply and demand, at local, regional, and national levels, so that the modality is listed and validated as a tourist segment.

Keywords: Tourist segmentation. Segmentation of the tourist offer; Geotourism.

\section{Resumen}

\section{Potencialidades del geoturismo para la creación de una nueva segmentación turística en Brasil}

El turismo como actividad económica se presenta desde segmentos turísticos, que agregan los productores, los distribuidores y los consumidores de los servicios en un espacio determinado. El Geoturismo aparece como una propuesta para un nuevo segmento, que valora el patrimonio natural y cultural, por medio de visitas e interpretación de atractivos abióticos. En este sentido, se propone discutir el Geoturismo como segmento turístico bajo el marco teórico del Ministerio de Turismo brasileño. Para ello, se realizó una investigación bibliográfica y documental desde las expresiones "geoturismo" y "segmento turístico" en producciones científicas y técnicas en las plataformas Google Scholar, Scopus y Biblioteca Brasileira de Teses e Dissertações. Los resultados demuestran que no existe consenso entre los estudiosos sobre la clasificación del Geoturismo como segmento turístico, pero los supuestos del Ministerio de Turismo brasileño le otorgan subsidios para que sea reconocido y prioritario en las políticas públicas de regionalización y sostenibilidad en el futuro. Se recomienda la construcción de una red integrada de oferta y demanda geoturística a nivel local, regional y nacional, para que la modalidad sea catalogada y validada como segmento turístico.

Palabras clave: Segmentación turística; Segmentación de la oferta turística; Geoturismo.

\section{INTRODUÇÃO}

O turismo é um fenômeno econômico e social (Organização Mundial do Turismo - OMT, 2020a), com sua origem na era moderna se dividindo nessas duas vertentes, a econômica e a sociológica (Panosso Netto, 2010). A primeira tende a ser valorizada em função da produtividade (emprego, renda, empresas etc.), enquanto a segunda o conservacionismo (natural e cultural).

Das classificações da economia do turismo há os chamados "segmentos turísticos". Dentre os inúmeros segmentos, há um movimento relativamente recente para consolidar uma atividade em novo segmento: o Geoturismo. 0 Geoturismo, trata-se de uma atividade que objetiva a visitação e interpretação de locais com recursos geológicos e correlacionados que, somados aos aspectos sociais, culturais e históricos das destinações, se configuram como atrativos turísticos. 
Para além da contemplação, o Geoturismo visa atrair pessoas com interesse em obter informações referentes aos patrimônios naturais e culturais. Longe de ser uma visita meramente de apreciação da paisagem, tem-se a abordagem da geodiversidade local, com enfoque na construção de conhecimento próprio, acerca das particularidades e características dos recursos geológicos. A geodiversidade aqui é entendida como "variedade natural (diversidade) de elementos geológicos (rochas, minerais, fósseis), geomorfológicos (formas de relevo, topografia, processos físicos), do solo e hidrológicos. Isso inclui suas assembleias, estruturas, sistemas e contribuições para a paisagem" (Gray, 2013) e trata-se do destaque principal na prática do Geoturismo.

0 entendimento acerca do Geoturismo como uma atividade independente, carece de atenção e debate, realizados por instâncias governamentais, bem como, advindos da análise científica de estudiosos da área de Turismo - e.g. bacharéis em Turismo (Moreira, 2010; Coutinho et al., 2019; Bento, Farias e Nascimento, 2020) -, que possam somar à reflexão de pesquisadores das Geociências - e.g. Geólogos e Geógrafos (Bento e Rodrigues, 2010; Castro e Ruchkys, 2017; Romão e Garcia, 2017; Pereira, 2017; Barbosa e Aquino, 2020) -, comumente envolvidos na temática.

Para tanto, considerou-se o marco teórico do Ministério do Turismo (Brasil, 2010a) a respeito da segmentação turística no Brasil e com ele examinar se a prática do Geoturismo pode defini-lo como um segmento turístico, em acordo com outras pesquisas correlatas (Coutinho et al., 2019; Bento, Farias e Nascimento, 2020). Cabe ressaltar que a valorização do meio ambiente e as novas tendências e discussões sociais, acadêmicas e econômicas elegeram o Ecoturismo - segmento reconhecido pelo MTUR e pela OMT - como norteador das ações. Contanto, privilegiando imensamente as questões - embora importantes - da fauna e da flora, ou seja, a conservação da biodiversidade. Assim, a base sustentadora destas paisagens (a geodiversidade), pouco valorizada, sendo considerada a "metade esquecida da conservação da natureza", ou seja, a geoconservação (Sharples, 2002). Hoje temos novas discussões e valorização de elementos que não estavam perceptíveis naquela visão ecoturística.

É possível encontrar diversos estudos científicos acerca da atividade, por meio da ótica de Geógrafos e Geólogos que fazem ponderações capazes de demonstrar, que a atividade geoturística, é uma ferramenta de disseminação de informação acerca da geodiversidade existente. Acarretando benefícios, como: melhor interpretação do meio ambiente, sensibilização da importância dessas localidades e, por conseguinte, busca pela conservação e manutenção do patrimônio natural. Vale salientar inúmeras pesquisas que mostram o avanço dessa temática, com destaque para as recentes análises bibliométricas (Moreira, 2010; Ruban, 2015; Pereira, 2017; Kuleta, 2018; Duarte et al., 2020; Herrero-Franco et al., 2020)

Diante disso, o presente artigo objetiva analisar o Geoturismo enquanto conceito com base nos documentos de segmentação turística do MTUR, buscando elucidar a relevância desta atividade, por meio de uma discussão teórico-conceitual acerca da segmentação turística. 


\section{METODOLOGIA}

O trabalho, de cunho exploratório e qualitativo, utilizou-se da pesquisa bibliográfica, que confere a consulta a materiais informacionais, livros, artigos e outros, que tratam sobre o tema estudado (Prodanov e Freitas, 2013). De modo a adquirir maior familiaridade com a segmentação turística no Brasil, utilizou-se livros, artigos de revistas indexadas, produções acadêmicas como dissertações e teses, e documentos elaborados pelo MTUR.

Para compor a fundamentação teórica desse estudo, fez-se uso de artigos nacionais e internacionais, dispostos nas plataformas Google Scholar e Scopus, utilizando como critérios de busca, primeiramente as expressões "geoturismo" e "segmentação turística"; e em segundo lugar expressões associadas, como "geodiversidade", "patrimônio geológico", "geoconservação" e "mercado turístico". Ainda nessa perspectiva, utilizou-se a Biblioteca Digital Brasileira de Teses e Dissertações - BDTD, alguns livros disponíveis no Google Books e livros impressos.

Além disso, realizou-se a pesquisa documental, que se trata da consulta a materiais que não receberam tratamento analítico, ou seja, são documentos disponíveis das formas mais dispersas e em fontes diversificadas, como por exemplo, em órgãos públicos ou empresas privadas, através de relatórios de pesquisa, diagnósticos, planos estratégicos, tabelas estatísticas, entre outros (Gil, 1991). Nesse sentido, analisou-se documentos oficiais do MTUR referentes a segmentação turística, tais como: o documento Marcos Conceituais (2006), o Programa de Regionalização do Turismo - Roteiros do Brasil (Brasil, 2007) e o documento Segmentação do Turismo e o Mercado (Brasil, 2010), entre outros, que foram acessados pelo site oficial do MTUR.

\section{SEGMENTAÇÃO TURÍSTICA}

Os estudos iniciais de segmentação turística remontam aos anos de 1970, com vista a definir tipos de turistas (Barretto e Rejowski, 2009). Para Ansarah e Panosso Netto (2010, p. 2):

A ideia de segmentar o mercado turístico, em qualquer destino, tem o mesmo significado semântico, qual seja: identificar pessoas com afinidades e desejos semelhantes que estejam dispostas a consumir um mesmo produto. As empresas turísticas fazem isso, pois podem desta forma conhecer melhor o seu consumidor e assim oferecer melhores produtos, cativando-os.

Para Beni (1998, p. 171) a segmentação é uma "técnica estatística que permite decompor à população em grupos homogêneos, e também à política de marketing que divide o mercado em partes homogêneas, cada uma com seus próprios canais de distribuição, motivações diferentes e outros fatores".

Por sua vez, para Lovelock e Wright (2001), segmento corresponde a "um grupo de clientes atuais e potenciais que compartilham as mesmas características, necessidades, comportamento de compra ou padrões de consumo". Compõe um segmento, sob a ótica da demanda turística, os indivíduos que já realizaram ou que têm pretensão de realizar viagens turísticas, adequando a oferta à demanda. 
Diante disso, o mercado turístico é composto por quatro elementos básicos: demanda turística, oferta turística, espaço geográfico e operadores de mercado (Brasil, 2010a).

Por demanda turística, entende-se as necessidades ou desejos de consumo de bens e serviços por um ou mais turistas em um destino visitado. Essa demanda influencia na oferta turística de determinados serviços, produtos, infraestruturas e segmentos de turismo nas mais variadas destinações.

Já a oferta turística é composta por elementos que, juntos, formam o produto turístico. São esses: os atrativos turísticos (naturais e/ou culturais); os serviços turísticos (meios de hospedagem, restauração, entretenimento e meios de transporte turísticos); a infraestrutura turística (serviços públicos de comunicação, financeiro, de saúde e outros); e a infraestrutura de apoio ao turismo (vias de acesso urbanos, saneamento, energia e outros que também são utilizados pela comunidade residente dos destinos turísticos) (Ignarra, 2003).

0 produto turístico é a:

Combinação de elementos tangíveis e intangíveis, como recursos naturais, culturais e artificiais, atrações, instalações, serviços e atividades em torno de um interesse específico que representa o núcleo do marketing do destino e cria uma experiência geral para o visitante, incluindo aspectos emocionais para os clientes potenciais. Um produto turístico é precificado e vendido através de canais de distribuição e tem um ciclo de vida (OMT, 2020, tradução nossa).

Remetendo-se a segmentação da demanda turística, pode ser realizada utilizando-se critérios tais como: idade; tipo de acompanhamento; nível de renda; espaço geográfico; duração da viagem; motivação da viagem; centros urbanos; e meios de transportes (Palhares, 2002; Ignarra, 2003, p. 30).

A seguir serão tratados à segmentação da oferta turística e a análise e discussão do geoturismo enquanto segmento turístico.

\section{SEGMENTAÇÃO DA OFERTA TURÍSTICA}

A oferta turística precisa estar alinhada às especificidades apresentadas pela demanda turística, sendo necessário analisar profundamente os pontos de vista da oferta e da demanda em um dado espaço, de forma que permita compreensão do perfil do visitante e, assim, formatar diferentes produtos que atenda àquele (Brasil, 2010a).

Nessa perspectiva, o MTUR lançou em 2006 o marco teórico a respeito dos segmentos prioritários no Brasil, com base na demanda: Turismo Rural, Turismo Cultural, Ecoturismo, Turismo Náutico, Turismo de Aventura, Turismo de Sol e Praia, Turismo de Negócios e Eventos, Turismo de Esportes, Turismo de Estudos e Intercâmbio, Turismo de Pesca, Turismo de Saúde e Turismo Social.

Para a identificação de tais segmentos observou-se nos destinos a existência de: "atividades, práticas e tradições (agropecuária, pesca, esporte, manifestações culturais e de fé); aspectos e características (geográficas, históricas, arquitetônicas, urbanísticas e sociais); e determinados serviços e infraestrutura (saúde, educação, eventos, hospedagem e lazer)" (Brasil, 2006, p. 3). 
Nota-se, assim, que o documento também compreende a segmentação a partir da oferta e, em função de uma demanda existente, leva em consideração a motivação das viagens dos turistas, o comportamento dos prestadores de serviços e da comunidade autóctone dos destinos. É válido ressaltar que, devido à natureza mutável dos padrões de consumo da demanda, é possível que surjam novas atividades turísticas e, consequentemente, novos produtos podem ser formatados, alimentando um ciclo de nova oferta, por fim, inclinando-se a um novo segmento.

Nesta linha, em 2020, a United Nations World Tourism Organization (UNWTO, 2020b) publicou definições de turismo, destacando 14 segmentos turísticos. A título de correlação do entendimento de segmentos turísticos entre as instituições de turismo mundial e nacional é possível verificar um certo alinhamento, com oito segmentos em comum, sendo quatro da OMT sem identificação com o do MTUR e seis deste com aquele (Quadro 1).

Quadro 1 - Correspondência entre os Segmentos Turísticos reconhecidos pelo MTUR (Brasil, 2006) e pela UNWTO (2020b)

\begin{tabular}{|c|c|}
\hline \multicolumn{2}{|c|}{ Segmentos Turísticos } \\
\hline Ministério do Turismo & Organização Mundial do Turismo \\
\hline Turismo Rural & Turismo Rural \\
\hline Turismo Cultural & Turismo Cultural \\
\hline Ecoturismo & Ecoturismo \\
\hline Turismo Náutico & 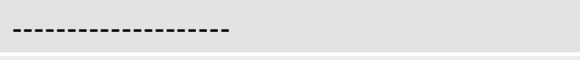 \\
\hline Turismo de Aventura & Turismo de Aventura \\
\hline Turismo de Sol e Praia & $\begin{array}{l}\text { Turismo Costeiro, Marítimo e de Águas } \\
\text { Interiores }\end{array}$ \\
\hline Turismo de Negócios e Eventos & Turismo de Negócios \\
\hline Turismo de Esportes & Turismo de Esportes \\
\hline Turismo de Estudos e Intercâmbio & 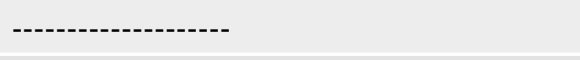 \\
\hline Turismo de Pesca & ------------------ \\
\hline Turismo de Saúde & Turismo de Saúde \\
\hline Turismo Social & 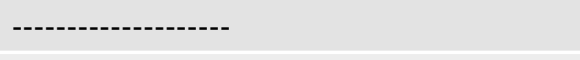 \\
\hline ------------------- & Turismo de Bem-Estar \\
\hline 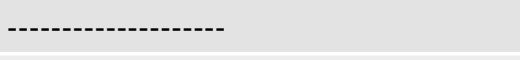 & Turismo de Montanha \\
\hline ------------------ & Turismo Gastronômico \\
\hline 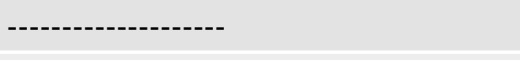 & Turismo Educacional \\
\hline 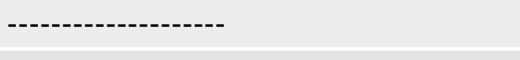 & Turismo Médico \\
\hline 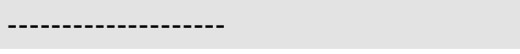 & Turismo Urbano/de Cidade \\
\hline
\end{tabular}

Fonte - Elaborado pelos autores (2020).

Com o intuito de organizar a oferta turística e seus atrativos, o MTUR propõe que seja realizada por meio da roteirização, que pode ser entendida como "um processo mercadológico direcionado a um produto específico - o roteiro turístico, enfatizando a tematização que assegura a identidade única do roteiro" (Brasil, 2010a, p. 33). 0 MTUR (Brasil, 2010a) enaltece ainda que, uma estratégia capaz 
de consolidar os roteiros turísticos e estruturar produtos se dá por meio da realização da segmentação turística.

Para que isso aconteça, uma estratégia utilizada é concernente à descentralização e compartilhamento do planejamento da atividade turística com as Unidades de Federação do país. Essa estratégia auxilia no fortalecimento e posicionamento do turismo, por meio da organização de regiões turísticas, que permitam reconhecer espaços regionais e segmentos turísticos importantes, que são desenvolvidos por meio do Programa de Regionalização do Turismo - Roteiros do Brasil, idealizado e executado pelos atores sociais da região (Brasil, 2013), a exemplo dos circuitos, rotas e estâncias turísticas, respectivamente dos estados de Minas Gerais (MG), Rio Grande do Sul (RS) e São Paulo (SP).

Baseando-se na compreensão da regionalização e da roteirização como formas de promover a segmentação turística, é lícito destacar a importância de pesquisas de mercado e, assim, propor um segmento turístico mais adequado. Desta forma, faz-se necessário compreender se existem indivíduos ou grupos que viajam com motivação relacionada ao segmento pretendido, buscando-se definir este perfil de demanda turística.

Em outro documento, o MTUR (Brasil, 2010a) evidencia que segmentos presentes nos roteiros turísticos são planejados e implementados com base na demanda turística, nas suas características sociais, econômicas, ambientais, culturais e outros. Sendo tarefa dos gestores públicos, da iniciativa privada e da sociedade civil organizada, o planejamento e elaboração da oferta turística através da realização de pesquisas, diagnósticos e análises referentes aos dados de caracterização da demanda turística (motivação, renda, procedência, instrução, trabalho/emprego etc.), as potencialidades presentes no território e os atrativos que podem se tornar produtos turísticos.

Assim, considerando-se o mix de Marketing, os 4 P's (Preço, Praça, Produto e Propaganda): existem no destino produtos formatados para o segmento? A comercialização desses produtos se dá por quem, como e onde são disponibilizados? Além disso, há questões econômicas, como: quais as contribuições econômicas geradas pelo segmento às empresas ofertantes de produtos e serviços locais? E sociológicas: quais os benefícios gerados às comunidades residentes?

O espaço geográfico por sua vez é o destino em si, onde ocorrem as relações entre oferta e demanda. Sua importância se deve ao levantamento, por exemplo de atrativos, características fisiográficas, culturais, sociais, de infraestrutura, entre outras necessárias à prática do segmento e à qualidade de vida da comunidade receptora.

Com isso, roteirizar pode contribuir com o levantamento e evidência das potencialidades existentes nos destinos. Acarretando em sua comercialização, pois "auxilia o processo de identificação, elaboração e consolidação de novos roteiros turísticos" (Brasil, 2010a, p. 33), e ainda, segmentar permite a estruturação e legitimação dos roteiros que primaram pela oferta turística pautada nas características locais e nas especificidades da demanda.

A escolha do tipo de turismo a ser implementado em um dado espaço deve primar pelo desenvolvimento sustentável. Afirma-se ainda que "a segmentação não tem uma receita certa ou uma única forma. É o resultado de uma combinação de fatores, de análises e de estratégias específicas para cada realidade" (Brasil, 2010a, p. 153).

Nessa perspectiva, para determinação de um novo segmento turístico a ser desenvolvido em um dado destino, tem-se como princípio norteador, além da 
demanda - seja ela real ou potencial -, o planejamento da implementação de segmentos que utilizem os recursos naturais e culturais com parcimônia, como é o caso do Geoturismo, que será discutido a seguir.

\section{GEOTURISMO ENQUANTO SEGMENTO TURÍSTICO}

Considerado como uma atividade turística praticada em vários destinos no mundo (Dowling e Newsome, 2006; Dowling e Newsome, 2010; Hose, 2016; Sadry, 2020; Singh, Wei e Anad, 2021), com destaque para visitação em espaços naturais (Mantesso-Neto et al., 2012), urbanos ou mistos (Garofano e Govoni, 2012), como unidades de conservação (Bento e Rodrigues, 2013), cidades (Liccardo; MantessoNeto; Piekarz, 2012; Del Lama, 2019) e geoparques - também aspirantes e projetos de geoparques (Farsani et al., 2012; Carvalho e Rudzewicz, 2015; Gürsay e Günes, 2014; Ngwira, 2015; Beretić, Dukanović e Checchini, 2019; Silva Filho e Maracajá, 2019) - o que não é diferente no Brasil (Manosso, 2007; Cruz, Steinke e Araújo Sobrinho, 2012; Moura-Fé, 2015).

Para promoção da discussão quanto ao Geoturismo, é lícito ressaltar que esse possui similaridades (e diferenças) no que tange ao Ecoturismo, sendo este último definido pelo MTUR (Brasil, 2010b, p. 16) como um segmento que "utiliza, de forma sustentável, o patrimônio natural e cultural, incentiva sua conservação e busca a formação de uma consciência ambientalista por meio da interpretação do ambiente, promovendo o bem-estar das populações". Percebe-se que, a esse segmento confere a prática de atividades em ambiente natural, tendo por intuito a conservação ambiental, cultural e social.

A United Nations Educational, Scientific and Cultural Organization (UNESCO, 1972) definiu ambientes que necessitam de conservação, por meio de sítios do patrimônio da humanidade. Estes, constituídos pelos patrimônios natural e cultural, são abordados no conceito de Ecoturismo. Por patrimônio natural, entende-se como o conjunto de recursos físicos, biológicos, geológicos, além do habitat de espécies de fauna e flora que são valorados do ponto de vista científicos e estético. Já o patrimônio cultural, trata-se dos monumentos com valor histórico, artístico e científico, como obras arquitetônicas, de escultura ou de pintura, elementos de caráter arqueológico e grutas. Em relação à compreensão e interpretação do patrimônio natural pelo Ecoturismo, infere atenção, habitualmente na biodiversidade, com a geodiversidade sendo tratada apenas enquanto contemplação da paisagem; já o Geoturismo, busca equilibrar o uso de ambos os patrimônios em sua prática, o que será evidenciado por meio da apresentação de suas definições neste tópico.

Tendo como intuito compreender o Geoturismo, na perspectiva de ser reconhecido como um segmento turístico no Brasil, analisou-se, seus conceitos e definições nacionais e internacionais visando compreender o surgimento da atividade, o seu significado e sua importância para a interpretação e conservação do meio ambiente. Nesse sentido, o início dos estudos sobre o Geoturismo deu-se em 1995, no Reino Unido, por meio do autor Thomas Hose, que entende o Geoturismo como uma forma recente, porém promissora de turismo (Hose, 1995).

Hose (1995), após identificar, que na década de 1980, havia localidades na Inglaterra com importantes características geológicas, que estavam se perdendo 
em função do mau uso, observou a necessidade de desenvolver mecanismos para explicar e promover a compreensão da importância da conservação desses recursos. Surge então, o Geoturismo como forma de identificar, promover e conservar a geodiversidade presente em locais de interesse turístico, motivando a obtenção de suporte público e político, além de gerar incrementos econômicos para a conservação, buscando contribuir e integrar a comunidade global das geociências - a exemplo da Rede Global de Geoparks da Unesco (2015) -, reconhecendo seu significado científico.

A atividade se dá pelo "fornecimento de instalações e serviços interpretativos para promover o valor e o benefício social de sítios geológicos e geomorfológicos e seus materiais, e para garantir sua conservação, para o uso de estudantes, turistas e outros recreacionistas casuais" (Hose, 2000, p. 136). Entende-se que o geoturismo inclui a visitação e o fornecimento de informações quanto aos recursos naturais, com destaque para a geodiversidade, a contemplação e a interpretação com geração de sentido e valor para a conservação.

É importante destacar que, devido à incipiência na difusão do significado científico e da importância social dos geossítios pelos geocientistas, o Geoturismo surge como precursor necessário para a geoconservação (Hose, 2011). Trata-se de uma atividade que busca proteger e manter os locais de interesse turístico em conjunto com as coleções de espécimes, arquivos e materiais existentes, reforçando a imprescindível necessidade de levar conhecimento e informação para a sociedade acerca da importância dos recursos geológicos (Hose, 2000).

A geoconservação compreende a gestão de locais de interesse geológico in situ e ex situ por meio de procedimentos específicos como inventário, avaliação, conservação, valoração e monitoramento (Henrique et al., 2011).

Diante disso, pode-se entender que os recursos geoturísticos ganham nova significação e interpretação quando trabalhados no Geoturismo (Coutinho et al. 2019), dando uma maior visibilidade à atividade, diferentemente de utilizar o patrimônio natural, apenas para fins contemplativos, conforme Aquino, Schänzel e Hyde (2018) (Figura 1).

Figura 1 - Estrutura conceitual sobre consumo do geoturismo e a produção de experiência, modificado de Aquino, Schänzel e Hyde (2018).

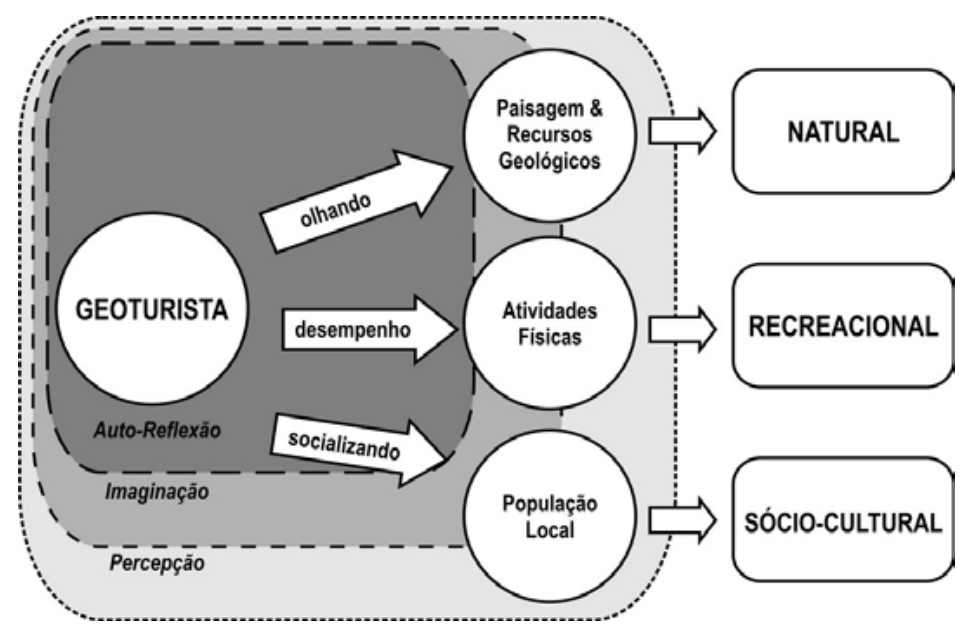

Segundo Conti, Elicher e Lavandoski (2021, p. 18) o geoturismo "talvez seja, atualmente, o campo de maior abrangência e crescimento quando se pensa numa 
atividade que alia visitação e ciência". As autoras destacam que já é uma realidade em alguns países, somando à relevância para sua segmentação pelo MTUR no Brasil.

Os indivíduos se envolvem com diversos recursos turísticos (incluindo o geológico) ao participarem do geoturismo. Os geoturistas são descritos como interagindo e consumindo esses recursos por meio do olhar, do agir e do socializar e por meio de processos psicológicos complexos que envolvem sua percepção, imaginação e autorreflexão. Por sua vez, pode-se produzir uma multiplicidade de experiências, neste caso centradas em três dimensões: natural, recreacional e sócio-cultural (Aquino et al., 2018).

No que compete ao público do Geoturismo, os geoturistas, Hose (2008) ressalta que existem dois grupos: Educacional (dedicated users) e o Recreativo (nondedicated users). 0 primeiro, refere-se àqueles indivíduos vinculados à instituições de ensino, seja qual for o nível de escolaridade, que buscam o desenvolvimento de estudos acerca dos recursos geológicos, à esses são ofertadas trilhas, por exemplo; e o segundo, aqueles indivíduos que são considerados amadores, que buscam pela visitação, contemplação e interpretação dos recursos geológicos, destinam-se a esses à visitação em geoparques.

Para Prendivoj (2018, p. 1), existem geoturistas latentes e arquetípicos. Estes "buscam oportunidades de construção de conhecimento" enquanto aqueles "chegam em busca de novas experiências turísticas". Enquanto para Grant (2010) entre os "geoturistas reais" há geoamadores, geoespecialistas e geoexperts, considerando seu geoconhecimento.

Nesse sentido, Hose (2012) identifica que emerge, o que ele chamou de Geoturismo moderno, onde sua premissa se baseia no movimento estético "romântico", que atraiu artistas modernistas para capturar as imagens dos recursos naturais, com visão literal e filosófica da terra. Essa visão modernista vem corroborar com o surgimento da prática popular do Geoturismo, pautada no tipo de geoturista que estava focado apenas na contemplação estética da paisagem, como locus amoenus e fugere urbem.

0 Geoturismo tem como foco a geodiversidade primando pelo desenvolvimento sustentável e pela conservação, ao buscar entender o recurso abiótico, enquanto atrativo, para compreender melhor este recurso, seu aspecto histórico e cultural (Dowling, 2011). É assim considerado, uma forma de turismo mais sustentável, pautado na geração equitativa de benefícios econômicos, sociais, ambientais e culturais a todos envolvidos com o Geoturismo (Newsome e Dowling, 2018) - interseção com o Turismo de Base Comunitária e o Ecoturismo -, e aspectos da geodiversidade e interrelações com atributos turísticos.

Desse modo, são perceptíveis as particularidades do Geoturismo, tais como: atenção dada à geodiversidade; ao ambiente de atuação que pode ser natural ou cultural; ao cunho informacional a que se propõe; entre outros aspectos, que o tornam uma prática diferente do Ecoturismo, mas que podem se coadunar.

Nesse sentido, Bento, Farias e Nascimento (2020), acrescentam que, a geodiversidade é o atrativo principal do Geoturismo, podendo ocorrer em áreas naturais e urbanas, o que nesta última não ocorre no ecoturismo, por exemplo.

Percebe-se ainda que, o Geoturismo se preocupa com a conservação ambiental ao mesmo tempo em que, sensibiliza para a interpretação dos recursos geológicos, acompanhado dos aspectos, sociais, históricos e culturais, o que beneficia tanto aos residentes que passam a conhecer e valorizar seu 
entorno habitual, quanto aos turistas, ao se gerar experiências mais originais em suas visitações (Lorenci, 2013).

É possível afirmar que os autores anteriormente citados apresentam uma visão uniforme do Geoturismo, focada na compreensão dos recursos geológicos como possíveis atrativos, o que pode ser considerado uma primeira vertente que conduz ao seu entendimento. Uma segunda vertente pode ser evidenciada por autores como Stueve, Cock e Drew (2002), Stokes, Cock e Drew (2003), Buckley (2003), dentre outros, que tratam do Geoturismo por meio do entendimento da utilização dos aspectos geográficos, de uma forma geral para a ocorrência da visitação.

Nessa segunda vertente, para Stueve et al., (2002), o Geoturismo relaciona-se estritamente com o turismo sustentável e se preocupa em manter o equilíbrio ecológico, social, econômico e cultural, além de mitigar os impactos que o turismo de massa ocasiona, pois, a atividade busca a conservação do caráter geográfico do destino e todos os atributos naturais e humanos que o compõem, atentando-se também aos impactos que suas atividades causam nas comunidades residentes, nas suas vidas e suas economias.

Stokes et al. (2003) afirmam que o Geoturismo abrange todos os aspectos da viagem, não apenas o meio ambiente. Sua definição compreende um turismo que sustenta ou aprimora o caráter geográfico do lugar que está sendo visitado; descreve os aspectos da sustentabilidade em uma viagem; e busca o fornecimento de uma viagem autêntica, através das experiências que os viajantes exigem.

Buckley (2003) corrobora com Stueve et al. (2002), ao afirmar que houve várias tentativas de definir termos que se relacionassem adequadamente ao que propõe o Geoturismo, onde seus aspectos estão relacionados às características culturais e naturais associadas em um determinado local geográfico que servem como atração para turistas.

Quanto a isso, o Geoturismo promove a conservação do ambiente, respeita e valoriza a cultura local e seu patrimônio. Reúne ainda aspectos naturais, históricos e culturais para gerar experiências de viagens mais autênticas aos turistas. Como benefícios do Geoturismo têm-se: a geração de emprego e renda para os residentes; apoio à manutenção da integridade dos locais visitados; informação e sensibilização de residentes e turistas sobre a herança natural, cultural e geológica do local; e a geração de conhecimentos que repercutem em experiências mais autênticas para os turistas (National Geographic, 2020).

Um exemplo é a agência de viagens GeoWorld Travel (2020), especializada em Geoturismo, que corrobora a definição apresentada pela European Geopark Network (2011) na Declaração de Arouca (Quadro 2):

Quadro 2 - Declaração de Arouca

\begin{tabular}{|l|l|}
\hline Diretrizes & Descrição \\
\hline $\begin{array}{l}\text { 1. Conceito de } \\
\text { geoturismo }\end{array}$ & $\begin{array}{l}\text { Turismo que sustenta e valoriza a identidade de um território, } \\
\text { tendo em consideração a sua geologia, ambiente, cultura, estética, } \\
\text { patrimônio e o bem-estar dos seus residentes. O turismo geológico é } \\
\text { um dos múltiplos componentes do geoturismo. }\end{array}$
\end{tabular}

(continua...) 
Quadro 2 - Continuação.

\begin{tabular}{|c|c|}
\hline Diretrizes & Descrição \\
\hline $\begin{array}{l}\text { 2. Conservar, } \\
\text { Divulgar e Valorizar a } \\
\text { Vida na Terra }\end{array}$ & $\begin{array}{l}\text { O turismo geológico é uma ferramenta básica para a conservação, } \\
\text { divulgação e valorização da história da Vida na Terra, incluindo suas } \\
\text { dinâmicas e mecanismos. Ele permite que os visitantes compreendam } \\
\text { o passado para ver o presente de outra perspectiva e projetar o futuro } \\
\text { compartilhados para a Terra e a humanidade. }\end{array}$ \\
\hline $\begin{array}{l}\text { 3. Valorizar o } \\
\text { patrimônio geológico }\end{array}$ & $\begin{array}{l}\text { A valorização do patrimônio geológico deve tentar abrir novos } \\
\text { caminhos e priorizar o uso de novas tecnologias sobre o uso de } \\
\text { cartazes de informação tradicionais. }\end{array}$ \\
\hline $\begin{array}{l}\text { 4. Veicular o } \\
\text { conhecimento e a } \\
\text { informação sobre o } \\
\text { património geológico }\end{array}$ & $\begin{array}{l}\text { O conhecimento e a informação sobre o patrimônio geológico devem } \\
\text { ser acessíveis e inteligíveis para o público em geral, devem ser } \\
\text { apresentados de forma facilmente compreensível para, evitando-se o } \\
\text { uso das informações com linguagem especializada e científica. }\end{array}$ \\
\hline $\begin{array}{l}\text { 5. Aplicar os } \\
\text { princípios básicos } \\
\text { de interpretação ao } \\
\text { patrimônio geológico }\end{array}$ & $\begin{array}{l}\text { Utilizar-se dos princípios básicos de interpretação e aplicá-los ao } \\
\text { patrimônio geológico. A interpretação de um espaço natural deve } \\
\text { provocar e despertar curiosidade e emoção muito mais do que ensinar. }\end{array}$ \\
\hline $\begin{array}{l}\text { 6. Incentivar } \\
\text { os territórios a } \\
\text { desenvolverem o } \\
\text { geoturismo }\end{array}$ & $\begin{array}{l}\text { O incentivo deve focar no meio ambiente, no patrimônio geológico, } \\
\text { no valor cultural, histórico e paisagístico do local. Além de envolver } \\
\text { os cidadãos e visitantes locais, ajudando a construir uma identidade } \\
\text { local e a promover o que é autêntico e único no território. Garantir ao } \\
\text { território e seus habitantes a integridade ambiental, justiça social e } \\
\text { desenvolvimento econômico sustentável. }\end{array}$ \\
\hline
\end{tabular}

Fonte - GeoWorld Travel (2020).

É possível perceber no exemplo da agência, que há no mercado internacional, empresas especializadas na prática do Geoturismo, que oferecem produtos turísticos diferenciados, para uma demanda que procura viagens focadas na geodiversidade, com passeios a geossítios, entre outros, de forma que não seja necessário ser conhecedor prévio de tais informações, o que torna o objetivo da viagem, a busca por conhecimentos dessas regiões e seus atrativos, acessível.

Nesse sentido, é categórico que o Geoturismo deve ser considerado como um novo segmento turístico, pois, trata-se de uma gama de atividades que infere atenção, tanto para a conservação da geodiversidade, quanto da biodiversidade, pois torna os produtos turísticos valoráveis para os residentes e turistas, diferenciando-se assim do ecoturismo e demais segmentos que ocorrem em ambientes naturais (Moreira, 2014). Ademais, o Brasil possui uma das maiores riquezas minerais e diversidade de paisagens do mundo, podendo ser uma economia conservacionista no ciclo de vida finito dos recursos naturais não renováveis, como parte dos abióticos. No entanto, o investimento em uma modalidade de turismo responsável com o conhecimento e o impacto nos recursos naturais, vem ao encontro de políticas públicas e iniciativas privadas pela educação, melhorando a qualidade de vida das populações e satisfazendo os turistas, em especial o doméstico ao estimular sentimento de pertencimento com seu patrimônio. 


\section{CONSIDERAÇÕES FINAIS}

Parte dos resultados do presente estudo demonstra que, do ponto de vista do MTUR a segmentação turística é relevante e necessária para compreensão da oferta com base na demanda turística. Com isso, os documentos analisados sugerem que para a oferta turística nos destinos, faz-se necessário à existência de características culturais, geográficas, além de infraestrutura, demanda, levantamentos estatísticos, políticas públicas do governo federal, gestão em nível local e criação de mais roteiros turísticos, que viabilize o geoturismo enquanto segmento nas destinações.

A partir da realização desse estudo o objetivo central foi atendido, na medida em que, foram evidenciados os documentos oficiais do MTUR que tratam da segmentação turística no Brasil, onde observou-se algumas orientações quanto a escolha de segmentos nos destinos turísticos, sendo eleitos conforme a existência de uma demanda, características locais e infraestruturas propícias a execução do segmento pretendido, bem como, do planejamento dos órgãos públicos e iniciativas privadas locais.

De forma análoga, a prática dos mais variados segmentos de turismo, tais como: Ecoturismo, Sol e Praia, entre outros, são executadas nos destinos que: melhor sustentem suas atividades, possuam as características ambientais (natural ou cultural), tenham infraestrutura adequada para atender às necessidades e desejos da comunidade residente e dos possíveis turistas, além da indispensável articulação entre o poder público e a iniciativa privada quanto ao planejamento e escolha do segmento a ser implementado na destinação.

No que concerne ao Geoturismo, pode ser compreendido como uma atividade que utiliza de forma sustentável, o espaço geográfico, seus aspectos constituintes, a geodiversidade/geopatrimônio e a biodiversidade, além dos aspectos culturais herdados por uma comunidade, e que devido a essa amplitude e importância quanto a seus atrativos, requerem proteção, a fim de evitar sua degradação ou desaparecimento. Tal proteção pode ser aliada a valorização e conservação dos diversos atrativos, por meio da sensibilização ambiental dos turistas e anfitriões, trazendo a esses últimos benefícios socioeconômicos.

Em suma, identificou-se que o Geoturismo apresenta características para se tornar segmento turístico. Tais como a prática de atividades que valorizam as tradições e os aspectos ambientais, geográficos, arquitetônicos, históricos etc. presentes nas destinações. Bem como, possui certo grau de serviços e infraestrutura, que embora destine-se a outros segmentos, podem vir a atender a uma demanda geoturística existente.

Com base nos documentos oficiais do MTUR, para que o Geoturismo possa ser considerado um segmento turístico, para além de estudos de reflexões conceituais, são necessárias diversas ações. Dentre elas pesquisas quantitativas e qualitativas que evidenciem: a existência de uma demanda significativa de produtos formatados e comercializados; os benefícios econômicos recebidos por operadores de turismo; e os benefícios sociais recebidos pela comunidade residente.

Ressalta-se que, estudos precisam destacar a existência de infraestruturas adequadas ao segmento e ao bem-estar da população, o que a princípio, ainda não é visto de forma completa no Brasil, dessa forma ainda não sendo possível encará-lo enquanto o segmento. 
Porém, pesquisas podem contribuir para considerar a viabilidade do Geoturismo e, futuramente, dar subsídios ao MTUR para o inserir no planejamento e divulgação da atividade, bem como, a possibilidade de que recursos financeiros sejam designados às destinações que se enquadrem a sua prática.

Remetendo-se às políticas públicas, o próprio MTUR (Brasil, 2018) afirma que, para promover destinos e produtos turísticos, necessita-se de critérios técnicos, além de considerar os segmentos turísticos e os mercados relevantes do país. Desse modo, a destinação de recursos para implantação de infraestruturas adequadas a um destino ou atrativo turístico, é pautada nos segmentos definidos pelo MTUR. Uma vez realizadas pesquisas que enalteçam a viabilidade do Geoturismo no Brasil, esse pode vir a ser considerado alvo de investimentos pelo poder público e privado, não havendo impedimentos para que o MTUR divulgue o geoturismo, mesmo ainda não sendo considerado um segmento.

De modo a contribuir nas reflexões do MTUR acerca do Geoturismo, as pesquisas gerarão dados e informações que auxiliem na compreensão da atividade com base nas vertentes conceituais tratadas neste estudo, possibilitando ao MTUR a tomada de decisão baseada em dados reais quanto a inserção do Geoturismo dentro de alguma segmentação, seja ela cultural ou em áreas naturais (Facuri, 2020).

O MTUR (Brasil, 2018, p. 94), evidencia que é necessário monitorar o ordenamento, estruturação e o desempenho das atividades direcionadas ao turismo e sugere aferir quais os impactos econômicos que a atividade gera, afirmando que "os impactos econômicos dos segmentos turísticos ainda são insuficientes", orientando "realizar estudos e pesquisas, de caráter qualitativo e quantitativo, sobre as características dos diversos segmentos da atividade turística".

Nessa perspectiva, recomenda-se que novas pesquisas científicas versem sobre o Geoturismo - em especial quanto à demanda e comercialização de produtos geoturísticos. Por meio, por exemplo, de mais abordagens qualitativas e quantitativas, que busquem o monitoramento dessa forma de praticar a atividade. De modo a verificar dados junto aos atores envolvidos e do próprio atrativo turístico, fornecendo subsídios às entidades governamentais, capazes de demonstrar: como tem se dado sua prática; quais são os atrativos dessa atividade; o que motiva a visitação a esses atrativos; e quais os impactos sociais, ambientais e econômicos deixados.

\section{REFERÊNCIAS}

Ansarah, M. G. R. \& Panosso Netto, A. (2010). A Segmentação dos Mercados como Objeto de Estudo do Turismo. Anais... Seminário da ANPTUR, p. 1-15.

Aquino, R. S., Schänzel, H. A., \& Hyde, K. F. (2018). Unearthing the geotourism experience: geotourist perspectives at Mount Pinatubo, Philippines. Tourist Studies, 18(1): 41-62.

Barbosa, R. N., \& Aquino, C. M. S. (2020). Análise bibliométrica do tema geodiversidade no Brasil em revistas no período 2010-2016 e suas regiões de concentração.Terr@Plural, 14: 1-14.

Barretto, M., \& Rejowski, M. (2009). Considerações epistemológicas sobre segmentação: das tipologias turísticas à segmentação de mercado. In: Panosso Netto, A. e Ansarah, M. G. R. (Eds). Segmentação do mercado turístico: ensaios, produtos e perspectivas. Barueri-SP: Manole, 2009, p. 3-18.

Beni, M. C. (1998). Análise Estrutural do Turismo. 13 ed. São Paulo: Senac. 
Bento, L. C. M., \& Rodrigues, S. C. (2010). O Geoturismo como instrumento em prol da divulgação, valorização e conservação do patrimônio natural abiótico - uma reflexão teórica. Turismo e Paisagens Cársticas, 3(2): 55-65.

Bento, L. C. M., \& Rodrigues, S. C. (2013). Geoturismo em unidades de conservação: uma nova tendência ou uma necessidade real? - estado da arte. Revista do Departamento de Geografia - USP, 25: 77-97.

Bento, L. C. M., de Farias, M. F., \& do Nascimento, M. A. L. (2020). Geoturismo: um Segmento Turístico? Revista Turismo: Estudos e Práticas, 9(1): 1-23.

Beretić, N., Đukanović, Z., \& Cecchini, A. (2019). Geotourism as a Development Tool of the Geo-mining Park in Sardinia. Geoheritage, 11: 1689-1704.

Brasil. Ministério do Turismo. (2006). Marcos conceituais. Recuperado de: http:// www.turismo.gov.br/sites/default/turismo/o_ministerio/publicacoes/downloads_ publicacoes/Marcos_Conceituais.pdf

Brasil. Ministério do Turismo. (2007). Programa de Regionalização do Turismo - Roteiros do Brasil: Módulo Operacional 7 Roteirização Turística. Brasília. 51 p. Recuperado de: http://www.turismo.gov.br/assuntos/5298-m\%C3\%B3dulos-operacionais-doprograma-de-regionaliza\%C3\%A7\%C3\%A3o.html

Brasil. Ministério do Turismo. (2010). Programa de qualificação a distância para o desenvolvimento do turismo: roteirização turística, promoção e apoio à comercialização. 2 ed. Brasília: SEaD/UFSC.

Brasil. Ministério do Turismo. (2010a). Segmentação do turismo e o mercado. Brasília: Ministério do Turismo. 170p.

Brasil. Ministério do Turismo. (2010b). Ecoturismo: orientações básicas. Ministério do Turismo, Secretaria Nacional de Políticas de Turismo, Departamento de Estruturação, Articulação e Ordenamento Turístico, Coordenação Geral de Segmentação. 2. ed. Brasília: Ministério do Turismo.

Brasil. Ministério do Turismo. (2013). Plano Nacional de Turismo 2013-2016: “0 Turismo fazendo muito mais pelo Brasil”. Recuperado de: http://www.turismo.gov.br/planonacional-do-turismo.html.

Brasil. Ministério do Turismo. (2018). Plano Nacional de Turismo 2018-2022 mais emprego e renda para o Brasil. Recuperado de: http://regionalizacao.turismo.gov.br/images/ PNT_2018-2022.pdf

Buckley, R. (2003). Environmental inputs and outputs in ecotourism: Geotourism with a positive triple bottom line? Journal of Ecotourism, 2(1): 76-82.

Carvalho, R. G. A., \& Rudzewicz, L. (2015). Uma análise do desenvolvimento do geoturismo em cinco geoparques brasileiros. Revista Turismo y Desarollo Local, 8(19): 1-14.

Castro, P. T. A., \& Ruchkys, U. (2017). Iniciativas sobre patrimônio geológico e temas correlatos no Quadrilátero Ferrífero, MG. Caderno de Geografia, 27(2): 314-331.

Conti, B. R., Elicher, M. J., Lavandoski, J. (2021). Revisão sistemática da literatura sobre Turismo Científico. Revista Brasileira de Pesquisa em Turismo, 15(2): 1-23

Coutinho, A. C. A., Urano, D. G., Mate, A. J. \& Nascimento, M. A. L. (2019). Turismo e Geoturismo: uma problemática conceitual. Revista Rosa dos Ventos, 11(4): 754-772.

Cruz, M. A., Steinke, V. A., \& Araujo Sobrinho, F. L. (2012). El geoturismo en el entorno del distrito federal (Brasil): Un análisis previo a la planificación turística regional. Estud. Perspect. Tur., 21(3): 778-797.

Del Lama, E. A. (2019). Potential for Urban Geotourism: Churches and Cemeteries. Geoheritage, 11: 717-728. 
Dowling, R. K. (2011). Geotourism's global growth. Geoheritage, 3(1), 1-13.

Dowling, R., \& Newsome, D. (2006). Geotourism: sustainability, impacts and management. Burlington: Elsevier Butterworth-Heinemann, 2.560p.

Dowling, R., \& Newsome, D. (2010). Global Geotourism Perspectives. Oxford: Goodfeloow Publishers Ltd., 250p.

Duarte, A., Braga, V., Marques, C., \& Sá, A. A. (2020). Geotourism and Territorial Development: a systematic literature review and research agenda. Geoheritage, 12 (65).

European Geopark Network (2011) Arouca Declaration. International Congress of Geotourism - Arouca 2011, Arouca, Portugal. Recuperado de: http://aroucageopark. pt/documents/78/Declaration_Arouca_EN.pdf

Facuri, N. (2020). Os Territórios Brasileiros Aspirantes a Geoparque frente às Instituições Nacionais. [Webinar]. Sociedade Brasileira de Geologia. Recuperado de: https://www. youtube.com/watch?v=G_DdqP4_gfw

Farsani, N. T., Coelho, C. O. A., \& Costa, C. M. M. (2012). Analysis of networking activities in geoparks as geotourism destinations. International Journal of Tourism Research, 16(1), 1-13.

Garofano, M., \& Govoni, D. (2012). Underground Geotourism: a historic and economic overview of show caves and show mines in Italy. Geoheritage, 4: 79-92.

GeoWorld Travel. (2020). Geotourism. Recuperado de: https://www.geoworldtravel.com/ geotourism.php

Gil, A. C. (1991). Como Elaborar Projetos de Pesquisa. 3. ed. São Paulo, Atlas. 176p.

Grant, C. (2010). Towards a typology of visitors to geosites. Annals... Second Global Geotourism Conference, Making Unique Landforms Understandable. Mulu, Sarawak, Malaysia, 17-20 April.

Gray, M. (2013). Geodiversity: Valuing and Conserving Abiotic Nature. London, Wiley Blackwell. 508p.

Gürsay, M. S., \& Günes, S. G. (2014). Geotourism and Sustainability: The Kizılcahamam Çamlıdere Geopark Case. Journal of Ankara Studies, 2(2): 203-215.

Henriques M. H, Reis R. P., Brilha J., Mota T. (2011). Geoconservation as an emerging geoscience. Geoheritage, 3:117-128.

Herrero-Franco, G., Montalván-Burbano, N., Carrión-Mero, P., Apolo-Masache, B., \& JayaMontalvo, M. (2020). Research trends in Geotourism: a bibliometric analysis using the scopus database. Geosciences, 10(379): 1-29.

Hose, T. A. (1995). Selling the story of Britain's stone. Environmental Interpretation 10(2):16-17.

Hose, T. A. (2000). European Geotourism - geological interpretation and geoconservation promotion for tourists. Barettino D.; Wimbledon W.A.P.; Gallego E. (eds) Geological Heritage: Its Conservation and Management. Madrid, Sociedad Geológica de España/ Instituto Tecnológico GeoMinero de España/ProGEO, 127-146.

Hose, T. A. (2008). Towards a history of geotourism: definitions, antecedents and the future. Geological Society, London, Special Publications, 300(1): 37-60.

Hose, T. A. (2011). The English origins of geotourism (as a vehicle for geoconservation) and their relevance to current studies. Acta Geographica Slovenica, 51(2): 343-359.

Hose, T. A. (2012). 3G's for modern geotourism. Geoheritage, 4(1-2): 7-24.

Hose, T. A. (2016). Geoheritage and Geotourism: a european perspective. Woodbridge: Boydell Press. 
Ignarra, Luiz Renato. (2003). Fundamentos do Turismo. 2 ed. São Paulo: Pioneira Thomson Learning.

Kuleta, M. (2018). Geodiversity research methods in geotourism. Geosciences, 8(197): 1-9.

Liccardo, A., Mantesso-Neto, V., \& Piekarz, G. F. (2012). Geoturismo urbano: educação e cultura. Anuário do Instituto de Geociências - UFRJ, 35(1): 133-141.

Lorenci, C. T. B. (2013). Geoturismo: uma ferramenta auxiliar na interpretação e preservação do patrimônio geopaleontológico da região central do Rio Grande Do Sul. Universidade Federal de Santa Maria UFSM, RS (Dissertação de Mestrado), Brasil.

Lovelock, Christopher, Wright, Lauren. (2001). Serviços: Marketing e Gestão. São Paulo: Saraiva.

Manosso, F. C. (2007). Geoturismo: uma proposta teórico-metodológica a partir de um estudo de caso no município de Apucarana-PR. Caderno Virtual de Turismo, 7(2): 47-56.

Mantesso-Neto, V., Mansur, K. L., Ruchkys, U., \& Nascimento, M. A. L. (2012). 0 que há de geológico nos atrativos turísticos convencionais no Brasil. Anuário do Instituto de Geociências - UFRJ, 35(1): 49-57.

Moreira, J. C. (2010). Geoturismo: uma abordagem histórico-conceitual. Turismo e Paisagens Cársticas, 3(1) 5-10.

Moreira, J. C. (2014). Geoturismo e interpretação ambiental. Ponta Grossa (PR), UEPG. 157p.

Moura-Fe, M. M. (2015). Geoturismo: uma proposta de turismo sustentável e conservacionista para a Região Nordeste do Brasil. Soc. \& Nat., 27(1): 53-66.

National Geographic. (2020) About Geotourism. Recuperado de: https://www. nationalgeographic.com/maps/geotourism/about/

Newsome, D., \& Dowling, R. (2018). Geoheritage and geotourism. In Reynard, E. \& Brilha, J. (Eds.) Geoheritage: assessment, protection, and management. Amsterdam, Elsevier, p. 305-321.

Ngwira, P. M. (2015). Geotourism and Geoparks: Africa's Current Prospects for Sustainable Rural Development and Poverty Alleviation. 2015. In: Errami, Ezzoura; Brocx, Margaret; Semeniuk, Vik (eds.) From Geoheritage to Geoparks: Case Studies from Africa and BeyondLondon: Springer, 2015, p. 25-34.

Palhares, G. L. (2002). Transportes Turísticos. São Paulo, Aleph. 347p.

Panosso Netto, A. (2010). 0 que é Turismo. São Paulo, Ed. Brasiliense. 127p

Pereira, L. F. (2017). 10 anos da pesquisa em geoturismo no Brasil: balanços e perspectivas. Revista Geografias, 14(1): 106-117.

Prendivoj, S. M. (2018). Tailoring Signs to Engage Two Distinct Types of Geotourists to Geological Sites. Geosciences, 8 (329): 1-27.

Prodanov, C. C, \& Freitas, E. C. D. (2013). Metodologia de trabalho científico: métodos e técnicas da pesquisa e do trabalho acadêmico. 2 ed. Novo Hamburgo: Universidade Freevale. $277 \mathrm{p}$.

Romão, R. M. M., \& Garcia, M. G. M. (2017). Iniciativas de Inventário e Quantificação do Patrimônio Geológico no Brasil: Panorama Atual. Anuário do Instituto de Geociências - UFRJ, 40(2): 250-265.

Ruban, D. A. (2015). Geotourism - a geographical review of the literature. Tourism Management Perspectives, 15: 1-15.

Sadry, B. N. (2020). The Geotourism Industry in the 21st Century: the origin, principles and futuristic approach. Burlington: Apple Academic Press Inc. 561p. 
Sharples, C. (2002). Concepts and principles of geoconservation. Tasmania, Australia: Tasmanian Parks \& Wildlife Service.

Silva Filho, V. P., \& Maracajá, K. F. B. (2019). Geoturismo: uma alternativa para o desenvolvimento do Geoparque Seridó com base nos exemplos dos geoparques Arouca e Naturtejo. Revista Turismo y Desarollo Local Sostenible, 12(27): 1-22.

Singh, R. B., Wei, D., \& Anand, S. (2021). Global Geographical Heritage, Geoparks and Geotourism. Singapore, Springer. 483p.

Stokes, A. M. A. M., Cock, S. D., \& Drew, D. (2003). Geotourism: The New Trend in Travel. National Geographic, Washington, DC.

Stueve, A. M., Cock, S. D., \& Drew, D. (2002). The Geotourism Study: Phase I Executive Summary. National Geographic, Washington, DC. 24p.

United Nations Educational, Scientific and Cultural Organization. (1972). Convenção para o patrimônio mundial, natural e cultural. Recuperado de: https://whc.unesco.org/ archive/convention-pt.pdf

United Nations Educational, Scientific and Cultural Organization. (2015). UNESCO Global Geoparks. Recuperado de: http://www.unesco.org/geoparks/

United Nations World Tourism Organization. (2020a). Why tourism? Recuperado de: https://www.unwto.org/why-tourism

United Nations World Tourism Organization. (2020b). Tourism definitions. Madri, Organização Mundial do Turismo. 58p.

Recebido em: $10 / 11 / 2020$

Aprovado em:15/04/2021

\section{CONTRIBUIÇÕES}

Gilmara Barros da Silva: Definição do problema de pesquisa e objetivos; Desenvolvimento da proposição teórica; Realização da revisão bibliográfica e fundamentação teórica; Escolha dos procedimentos metodológicos; Coleta de dados; Análise de dados; Elaboração de tabelas, gráficos e figuras; Redação do manuscrito; Adequação do manuscrito às normas da RTA.

Rafaely Moreira Sabbá Neiva: Definição do problema de pesquisa e objetivos; Desenvolvimento da proposição teórica; Realização da revisão bibliográfica e fundamentação teórica; Escolha dos procedimentos metodológicos; Coleta de dados; Análise de dados; Elaboração de tabelas, gráficos e figuras; Redação do manuscrito; Adequação do manuscrito às normas da RTA.

Ricardo Eustáquio Fonseca Filho: Realização da revisão bibliográfica e fundamentação teórica; Análise de dados; Elaboração de tabelas, gráficos e figuras; Revisão crítica do manuscrito.

Marcos Antonio Leite do Nascimento: Definição do problema de pesquisa e objetivos; Desenvolvimento da proposição teórica; Realização da revisão bibliográfica e fundamentação teórica; Escolha dos procedimentos metodológicos; Coleta de dados; Análise de dados; Revisão crítica do manuscrito; Redação do manuscrito. 